\title{
NECESSIDADE OU EXAGERO? ANÁLISE DA UTILIZAÇÃO DE ARMAS DE FOGO PELOS GUARDAS MUNICIPAIS DO RIO DE JANEIRO
}

\section{ARTIGO ORIGINAL}

SERPA, Rodrigo Moraes ${ }^{1}$

SERPA, Rodrigo Moraes. Necessidade ou exagero? Análise da utilização de armas de fogo pelos Guardas Municipais do Rio De Janeiro. Revista Científica Multidisciplinar Núcleo do Conhecimento. Ano 04, Ed. 08, Vol. 02, pp. 05-17. Agosto de 2019. ISSN: 2448-0959

\section{RESUMO}

Uma discussão gira em torno da segurança pública em âmbito nacional: guardas municipais e a utilização de armas de fogo. Automaticamente, nesse imbróglio está a maior guarda municipal desarmada do país, a da capital do Rio de Janeiro, e uma vontade política demonstrada na câmara municipal do emprego de armamento. Atualmente o projeto que autoriza o emprego bélico encontra-se em tramitação com 20 vereadores coautores e 6 apoiadores, demonstrando real possibilidade de aprovação. Diversas capitais já utilizam arma de fogo, como: Salvador, Minas Gerais, São Paulo, Curitiba, entre outras. Dessa forma, esse estudo técnico consistiu em realizar uma análise da necessidade do uso de armamento letal pela guarda municipal do Rio de Janeiro, ou se havia exagero em tal pensamento. Foi realizada uma pesquisa descritiva e documental, buscando dados de violência da capital, o perigo que os agentes estavam sujeitos em detrimento da função e a opinião dos servidores

\footnotetext{
${ }^{1}$ Especialista Lato Sensu em Gestão Estratégica de Pessoas (Faculdade Educacional da Lapa - FAEL), também em Gestão Pública Municipal (Universidade Federal Fluminense - UFF) e Tecnólogo em Segurança Pública pela Universidade Estácio de Sá (UNESA). Guarda Municipal da cidade do Rio de Janeiro e Tutor de vídeo monitoramento da Secretaria Nacional de Segurança Pública (SENASP - MJSP).
} 
guardas municipais cariocas onde conclui-se que existe a necessidade do emprego bélico para proteção de si e de terceiros, sendo descartado exagero devido aos riscos oriundos do cumprimento de suas funções cotidianas e atribuições legais.

Palavras-chave: Arma de fogo, segurança pública, Guarda Municipal, Guarda Civil Metropolitano.

\section{INTRODUÇÃO}

Uma discussão retorna à Câmara Municipal do Rio de Janeiro em 2019: o armamento da guarda municipal da capital. O tema chegou a ser debatido em 2018, porém foi arquivado após a proposta feita pelo vereador e então presidente da Câmara Jorge Felippe, de autorizar apenas o armamento não letal. $O$ vereador e guarda municipal licenciado Jones Moura junto com 19 coautores e 6 vereadores apresentaram o Projeto de Emenda à Lei Orgânica № 23/2018 que pretende autorizar o uso de armas de fogo pela guarda municipal da capital carioca ${ }^{[2]}$. Para que a instituição possa portar armas de fogo deve-se existir alteração da lei orgânica municipal, onde existe proibição em seu art. 30 "VII - instituir, conforme a lei dispuser, guardas municipais especializadas, que não façam uso de armas (...)" (RIO DE JANEIRO, 1990, p. 23).

Tal contextualização gera debates, onde alguns entendem que as guardas municipais apenas poderiam ser criadas para proteger os bens, serviços e instalações municipais, assim não sendo útil esse armamento de fogo, tratando-se de um exagero, como decidido pela população da cidade de Niterói, quando foi realizado plebiscito e negado por 13.478 dos 18.991 votantes $^{[3]}$. Todavia, com o crescimento da criminalidade urbana, os referidos agentes ganharam destaque na colaboração direta com a segurança pública. Santos $(2018$, p. 37$)$ conclui que "armar a Guarda Municipal seja essencial para seu funcionamento apropriado, porque como já foi expresso ela é um ente do Estado e que para meliantes e afins, não passa de mais uma polícia".

O investimento público para prover armas de fogo é substancial, assim como demanda um treinamento constante. Portanto, é importante entender esse fenômeno e analisar em qual ponto a utilização de armas de fogo contribui diretamente para o 
interesse público e benefício da população. A utilização do armamento deve ser amplamente debatida e o resultado "não pode ser levado como uma questão de se posicionar contrário ou favorável, mas sim no que se refere à adequação do armamento ao que a instituição faz" (MIRANDA et al., 2008).

Dentro dessa temática, o objetivo geral do presente trabalho foi responder a seguinte pergunta: existe necessidade, ou configura-se um exagero, a utilização de armas de fogo pela guarda municipal da cidade do Rio de Janeiro? Para atingir o objetivo geral foram traçados três objetivos específicos: 1) identificar os dados de violência atuais da capital carioca, em crimes de possível atuação dos guardas municipais, 2) identificar se os agentes municipais possuem ocorrências que envolvam risco de vida em seu cotidiano e, 3) identificar se os guardas municipais são favoráveis à utilização de armas de fogo.

O tema é atual e de suma importância nesse cenário de tamanha preocupação com a violência urbana, e a guarda municipal além de um órgão de segurança pública, pode contribuir com a sensação de segurança, gerando um benefício direto para a população da cidade do Rio de Janeiro. Essa pesquisa foi dividida em referencial teórico, onde foi abordado alguns aspectos legais do emprego de armas de fogo pelos servidores da guarda municipal, o percurso metodológico utilizado, apresentação dos resultados e, por fim, as considerações finais e as conclusões do trabalho.

\section{FUNDAMENTAÇÃO TEÓRICA}

Conforme IBGE (2012a), em 2012, dos cinco mil quinhentos e sessenta e cinco (5.565) municípios brasileiros, 993 possuíam guardas municipais, ou seja, 17,8\% dos municípios. Já dos 92 municípios do Rio de Janeiro, 74 possuíam guarda municipal (IBGE, 2012b).

Na discussão sobre o uso de armamento de fogo, é basilar se atentar na Lei Federal no 10.826/2003 (Estatuto do Desarmamento), que trata sobre a possibilidade de utilização de armas de fogo pelos guardas municipais. Conforme Cardeal (2015), a referida legislação previu que somente os municípios com mais de 500 mil habitantes 
poderiam ter guardas municipais armados, onde os municípios entre 50 mil habitantes e 500 mil habitantes podem ter suas guardas armadas, porém os integrantes nesse caso só podem portar em serviço. Há vedação da utilização de armas de fogo pelos integrantes das guardas municipais onde a cidade possua menos de 50 mil habitantes. Tal restrição acaba atribuindo tratamento desigual por critério numérico de habitantes (DA SILVA; CASAGRANDE, 2010).

O Supremo Tribunal Federal, com base na Medida Cautelar - ADI no 5.948 (Relator Min. Alexandre de Moraes), concedeu medida liminar para suprimir a diferenciação supracitada, onde, em um primeiro exame, mesmo que em decisão monocrática, entende que fere "os princípios da igualdade e da eficiência" (BRASÍLIA, 2018, p.5):

CONCEDO A MEDIDA CAUTELAR PLEITEADA, ad referendum do Plenário, DETERMINANDO A IMEDIATA SUSPENSÃO DA EFICÁCIA das expressões das capitais dos Estados e com mais de 500.000 (quinhentos mil) habitantes, no inciso III, bem como o inciso IV, ambos do art. $6^{\circ}$ da Lei Federal no 10.826/2003. (BRASÍLIA, 2018, p. 16).

Foi sancionada, pela presidente Dilma Rousseff em 2014, a Lei Federal ㄲo 13.022 que implementa o Estatuto Geral das Guardas Municipais, mencionando em seu art. 2 que as guardas municipais, instituições de caráter civil, uniformizadas e armadas, conforme previsto em lei, é autorizada a portar arma de fogo. Em se tratando do art. 3 da referida lei - incisos II, III e V, tem-se como os princípios mínimos de atuação das guardas municipais: a preservação da vida, redução do sofrimento, diminuição de perdas, o patrulhamento preventivo e o uso progressivo da força. Entende-se como força "toda intervenção compulsória sobre o indivíduo ou um grupo de indivíduos, reduzindo ou eliminando sua capacidade de auto decisão". (BARBOSA; ÂNGELO, 2001, p. 107).

Segundo Diniz et. al. (2011) a força em uma ocorrência pode ser usada desde conflitos que vão à negociação até a imposição pacífica de obediência, porém conforme Metelo (2013) deve ser utilizada de maneira pontual e, se possível, seletiva à medida da reação, buscando atingir os objetivos específicos do caso. Já na definição de Dias et. 
al. (2009) o uso progressivo da força consiste na seleção adequada de opções de força pelo agente de segurança pública em detrimento do nível de submissão ou controle do suspeito ou infrator que deve ser controlado. Para Moreira e Corrêa (2001, p. 66) o "nível de uso da força é entendido desde a simples presença policial em uma intervenção até a utilização da arma de fogo, em seu uso extremo (uso letal)".

Se o uso progressivo da força é um princípio mínimo de atuação e pode se atingir o risco de letalidade, por que a guarda municipal do Rio de Janeiro não utiliza armas de fogo? Segundo Baierle e Merlo (2008), se referindo a guarda municipal de Porto Alegre, essa não é uma questão fácil, onde alguns defendem a utilização em todos os postos de trabalho, outros em determinadas funções, onde curiosamente o pessoal mais operacional acaba sendo voz contrária a utilização de armas, talvez por identificar no cotidiano de trabalho que a arma é o último recurso, assim sendo um atrativo ao criminoso e um risco ao guarda.

Corroborando, Sandro Júnior et. al (2017) identificaram que o porte de armas de fogo pela guarda municipal de Volta Redonda, no Estado do Rio de Janeiro, não é necessário, uma vez que as atividades que os servidores possuem não demandam tal uso, ressaltando que os servidores já se utilizam de tal equipamento.

(...) recomenda-se o uso do presente artigo por pesquisadores, acadêmicos e a sociedade em geral, que visem o conhecimento da atuação local e específica de uma Guarda Municipal. Como proposição para novos estudos, os autores poderão abranger os municípios vizinhos e ter uma visão efetiva de toda a região. (SILVA JÚNIOR et. al, 2017, p. 12)

\section{PROCEDIMENTOS METODOLÓGICOS}

Para atingir o objetivo geral da presente pesquisa foi necessário traçar a natureza da pesquisa, sendo a mesma aplicada. A forma de abordagem se dará tanto quantitativa quanto qualitativa. Segundo Raupp e Beuren (2006, p. 76) "a busca pelas respostas para problemas de pesquisa, por meio de delineamentos, é um processo cíclico, uma 
vez que não termina com a resposta obtida". Quanto ao tipo de pesquisa, o artigo é revestido de pesquisa descritiva, que possui o objetivo de delinear as características de determinada população ou fenômeno, onde "são incluídas nesse grupo as pesquisas que têm como objetivo levantar as opiniões, atitudes e crenças de uma população" (GIL, 2008, p. 28).

Com relação ao primeiro e ao segundo objetivos específicos, que buscavam analisar o índice de violência da capital fluminense, foi levantado documentalmente através do Anuário Brasileiro de Segurança Pública, dados que auxiliem a identificar atos criminosos que os servidores da guarda municipal do Rio de Janeiro podem se deparar em patrulhamento preventivo nas ruas cariocas, a fim de mensurar o nível de risco a qual os agentes estão submetidos.

A Guarda Municipal do Rio de Janeiro realizou pesquisa de opinião pela sua plataforma de intranet, questionando se os guardas municipais eram a favor da utilização de armas de fogo, onde era possível apenas responder "sim" ou "não". A indagação ficou disponível no portal entre os dias 12/02/2019 e 28/02/2019, onde só era possível responder realizando autenticação no sistema por meio de login e senha onde mais de $80 \%$ foi favoráve[ ${ }^{[4]}$.

Buscando a resposta ao terceiro objetivo específico, foi realizada pesquisa através de questionário em um universo de 7.533 guardas com amostragem de 300 agentes, a fim de entender a opinião além do "sim" e do "não" proposto pela autarquia municipal. O meio para difusão foi pelas duas redes sociais virtuais mais utilizadas no país atualmente, Facebook e WhatsApp. Para Costa (2014, p. 20) o Facebook por conta das suas características é um meio propício para realizar pesquisas científicas, pois é a rede social virtual mais utilizada pelos brasileiros, e suas ferramentas dão a possibilidade de diversas formas de coletas de dados, podendo "persuadir os participantes, obter apoio (curtir, compartilhar, comentar) e viralizar/expandir as fronteiras de contato". Para Serres (2013) para atingirmos a nova geração, o WhatsApp é um recurso eficiente, que pontua fatores como a conectividade e acessibilidade à todas as pessoas, de todos os lugares, a todo o saber. Não houve característica específica do respondente, necessitando apenas ser guarda municipal 
da cidade do Rio de Janeiro. Os quatro questionamentos fechados e o campo aberto foram geridos pela plataforma da Survey Monkey ${ }^{[5]}$, e ficaram ativos entre os dias 21/03/2019 e 28/03/2019.

Quadro 1- Perguntas realizadas aos guardas municipais

\begin{tabular}{|l|l|}
\hline PERGUNTA & TIPO \\
\begin{tabular}{|l|l|} 
Quanto tempo você trabalha na instituição como guarda \\
municipal?
\end{tabular} & $\begin{array}{l}\text { Fechada (Opção 1 a } 25 \\
\text { ou mais) }\end{array}$ \\
\hline $\begin{array}{l}\text { Qual setor você trabalha atualmente? } \\
\text { Fechada (Operacional ou } \\
\text { administrativo) }\end{array}$ \\
$\begin{array}{l}\text { Você é a favor do uso de armas de fogo pela guarda } \\
\text { municipal do Rio de Janeiro? }\end{array}$ & Fechada (Sim ou não) \\
\hline $\begin{array}{l}\text { Você já se envolveu em alguma ocorrência onde a } \\
\text { utilização de arma de fogo seria necessária para a } \\
\text { resolução? }\end{array}$ & Fechada (Sim ou não) \\
\hline $\begin{array}{l}\text { Opcionalmente, caso a resposta da pergunta anterior } \\
\text { tenha sido "sim", discorra sobre a(s) ocorrência(s): }\end{array}$ & Aberta \\
\hline
\end{tabular}

Fonte: Elaborado pelo autor

\section{APLICAÇÃO E RESULTADOS}

Os índices de violência da capital fluminense cresceram, conforme o Anuário Brasileiro de Segurança Pública (ANUÁRIO, 2018), A categoria Mortes violentas intencionais (MVI) mostram que na cidade do Rio de Janeiro foi registrada a evolução do número de mortes violentas: de 1.950 para 2.131, de 2016 para 2017[6].

O índice de homicídios dolosos também evoluiu. Em 2016 era de 1.330, passando para $1.492 \mathrm{em} 2017$, variando em $11,8 \%$. Acompanhando o crescimento, está a taxa de latrocínios por número de vítimas na comparação entre 2016 e 2017, onde subiu de 88 para 93, numa variação de $5,3 \%$. O índice de roubo de veículos passou de 19.314 em 2016 para 25.894 em 2017, com variável crescente de 31,9\%, assim como 
o de furto de veículos, que passou de 6.710 em 2016 para 6.839 em 2017, com variação em $0,3 \%$.

Ainda segundo o anuário, o índice de estupros evoluiu de 1.392 em 2016 para 1.438 em 2017, variando em 3\%, ficando atrás apenas da capital São Paulo. O índice de feminicídios evoluiu de 16 em 2016 para 68 em 2017, gerando variação de 322,9\%. Já o nível de roubo a transeunte foi de 93.818 em 2016 para 85.993 em 2017, retraindo $8,8 \%$, mesmo ainda se mantendo em um patamar elevado.

Alguns dados de violência apresentaram redução: lesão corporal seguida de morte (por número de vítimas) era de 28 em 2016 para 19 em 2017, numa variação negativa de 32,4\%. Já o índice de lesão corporal dolosa em violência doméstica (homens e mulheres vítimas) reduziu de 26.946 em 2016 para 24.477 em 2017, variando negativamente em 9,6\%. A taxa de homicídio de mulheres sofreu uma leve redução, onde em 2016 era de 396 e passou para 381 em 2017, retraindo em variação negativa de $4,3 \%$.

O índice de registros de apreensão de armas de fogo realizado pelas secretarias estaduais retraiu de 9.010 em 2016 para 8.706 em 2017 (variação negativa de 3,9\%) onde as mesmas ocorrências obtiveram crescimento pela Polícia Rodoviária Federal, variando 107\% (137 em 2016 para 285 em 2017). As ocorrências que envolvem porte ilegal de arma de fogo reduziram de 3.620 em 2016 para 3.207 em 2017, com variação negativa de $11,8 \%$. As mortes decorrentes de intervenções da polícia civil e militar, dentro e fora do serviço, foram em um total de 504 em 2016 para 527 em 2017, variável de 4,6\% (ANUÁRIO, 2018).

A análise do questionário apresentado aos guardas municipais foi realizada e os seus dados tabulados. No primeiro questionamento, onde buscava saber quantos anos possuía na corporação, a fim de apurar o tempo de instituição dos respondentes, apresentou-se o quantitativo de 14 servidores com 0 a 4 anos (4,67\%), 105 com 5 a 10 anos (35\%), 24 com 11 a 15 anos (8\%), 57 com 16 a 20 anos (19\%), 63 com 21 a 25 anos (21\%) e $37 \mathrm{com}$ mais de 25 anos (12,33\%), demonstrando que tanto servidores mais novos quanto mais experientes participaram. 
Figura 1- Demonstrativo do primeiro questionamento

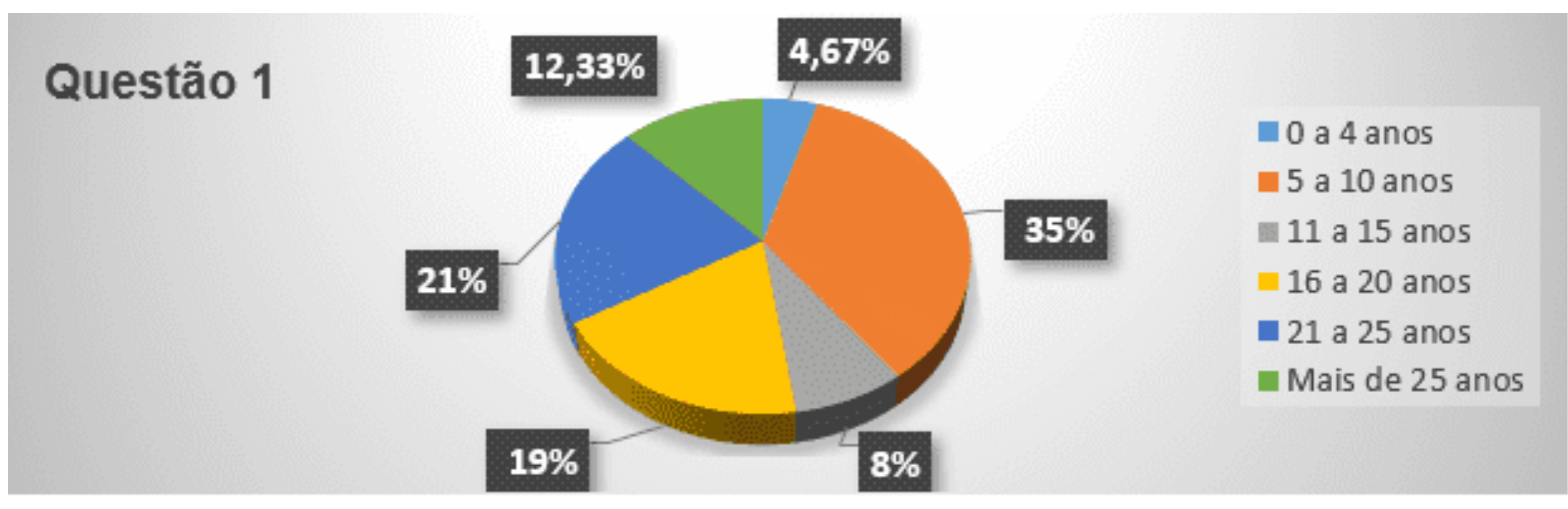

Fonte: Elaborado pelo autor

O segundo questionamento que indagava onde o guarda municipal trabalhava (se em setor administrativo ou operacional) a fim de analisar a real situação do respondente relacionado ao uso de arma de fogo, foram registrados 230 servidores laborando em setor operacional $(76,67 \%)$ e 70 em setor administrativo $(23,33 \%)$ onde os servidores que trabalham em funções administrativas com mais de 10 anos de serviço são a maioria (55).

Figura 2- Demonstrativo do segundo questionamento

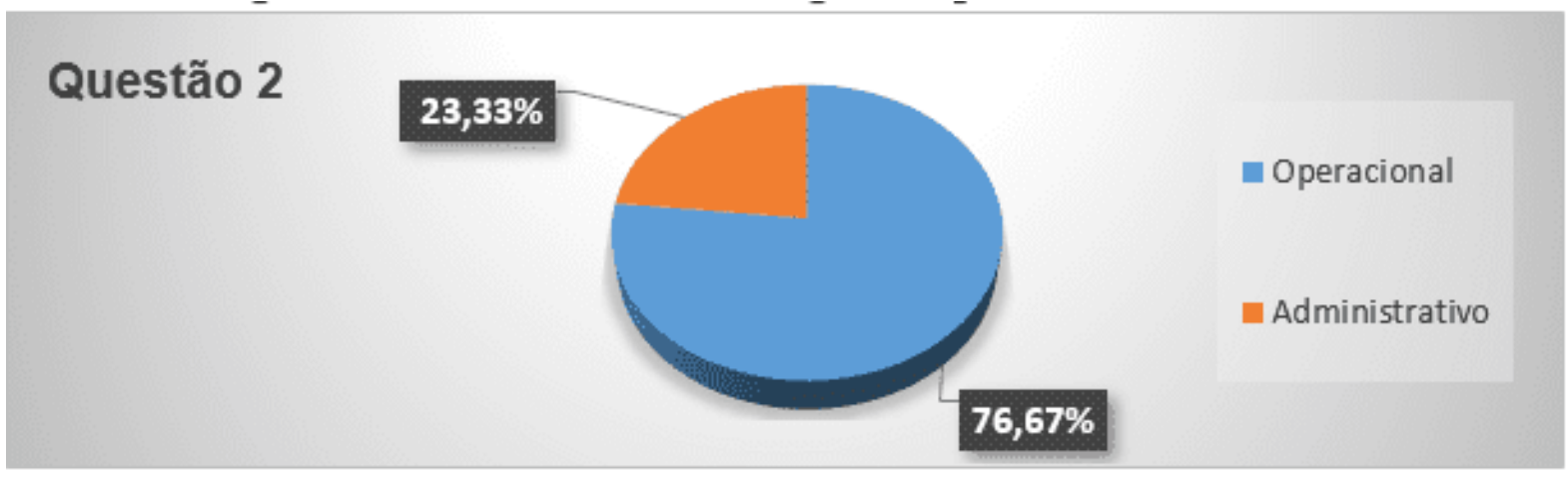

Fonte: Elaborado pelo autor

Quando perguntados se são a favor ou contra a utilização de armas de fogo pelos guardas municipais do Rio de Janeiro, 267 guardas municipais responderam que sim (89\%), 23 que não $(7,67 \%)$ e $10(3,33 \%)$ mencionaram não possuir opinião formada 
sobre o assunto. A quantidade de respostas a favor é expressiva, corroborando com a pesquisa realizada pela instituição anteriormente.

Figura 3- Demonstrativo do terceiro questionamento

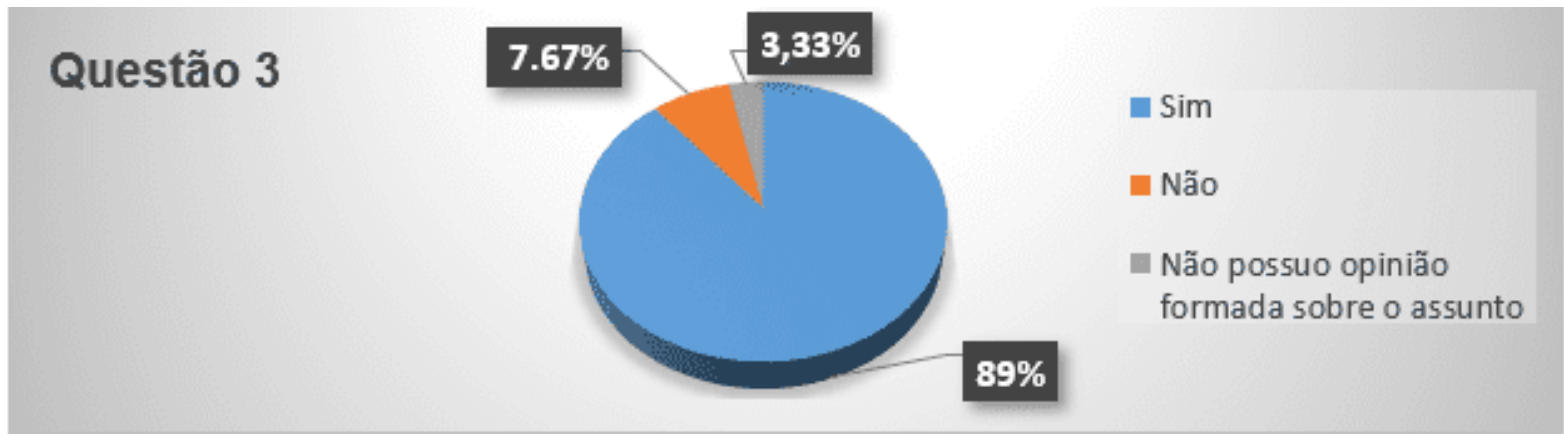

Fonte: Elaborado pelo autor

Analisando o quarto questionamento, que perguntava ao respondente guarda municipal se já se envolveu em alguma ocorrência onde a arma de fogo seria necessária para a resolução da ocorrência, 206 servidores $(68,67 \%)$ responderam que sim, e 94 (31,33\%) que não, quantitativo também expressivo em relação à amostragem.

Figura 4- Demonstrativo do quarto questionamento

\section{Questão 4}

\section{$31,33 \%$}

m $\operatorname{Sim}=$ Não

$68,67 \%$

Fonte: Elaborado pelo autor

No último campo do questionário (5), de maneira opcional, foi disponibilizado para aqueles que responderam "sim" na questão quatro (4), um campo aberto para que os servidores pudessem discorrer sobre a(s) ocorrências(s) que tiveram participação 
onde seria necessária a utilização de arma de fogo, onde 134 guardas municipais responderam e 166 se omitiram.

Após levantamento qualitativo, verificou-se que a maior quantidade de respostas se refere a ocorrência dos servidores quando em patrulhamento nas ruas se depararam com situações criminosas de assalto ao cidadão ou a estabelecimentos (casa lotérica, banco, etc.), ou foram chamados pela população para atuar em apoio, todavia sem sucesso pela falta de equipamento.

Em menor proporção, porém ainda relevante, alguns textos citavam ameaças durante o trabalho de trânsito e de ordenamento urbano, onde o envolvido ou um grupo deles apontou arma de fogo, o obrigando a se evadir do local ou não infracionarem veículos pela região, sob pena de "se ver com eles", ou se recusar a entregar mercadoria apreendida legalmente sacando uma arma para intimidar.

O respondente número 67 informou que trabalhava atualmente no Programa Rio + Seguro[7], onde a guarda municipal atua em conjunto com a Polícia Militar no patrulhamento e nas abordagens, onde já foram efetuadas prisões de infratores da lei com armas de fogo e por sorte não houve resistência, pois se houvesse não teria como se defender pois não estava nem com arma de fogo para repelir a injusta agressão, nem colete balístico.

Ressalta-se que o respondente número 211 ignorou as informações ora descritas e mesmo respondendo "não" na questão 4, respondeu à questão qualitativa, reiterando que não era a favor da utilização de armas de fogo, pois classificou a instituição como política e que os servidores seriam cassados nas ruas e não teriam apoio jurídico da autarquia.

Em um caso atípico, o respondente número 234 mencionou na questão 3 que não é a favor da utilização de armas de fogo pela instituição, e na questão 4 citou que já se envolveu em ocorrência onde o material bélico seria necessário para a conclusão da ocorrência, justificando seu pensamento dizendo que muitos servidores residem em área de risco, sendo este um fator preponderante de sua negativa, pois muitos 
guardas municipais teriam que sair de suas residências às pressas devido ao perigo, e que poderia mudar sua opinião caso antes fosse realizada uma estruturação na instituição objetivada em sanar tal imbróglio.

\section{CONSIDERAÇÕES FINAIS}

A problemática envolvendo a atuação dos guardas municipais no tocante a segurança pública e a utilização de armas de fogo possuem extrema relevância em todo território nacional.

O objetivo geral da pesquisa foi analisar a real necessidade da utilização pelos guardas municipais da capital do Rio de Janeiro de tal emprego bélico, ou se existia um exagero nesse raciocínio, onde especificamente buscou-se analisar os dados de violência urbana a fim de apurar os níveis de evolução, assim como apurar a opinião dos guardas municipais da cidade do Rio de Janeiro e um possível risco de morte devido a suas atribuições legais. Com o intuito de buscar as respostas da solução geral, foi utilizada pesquisa documental através de levantamento no Anuário Brasileiro de Segurança Pública e de questionário aplicado diretamente aos guardas municipais.

A atribuição dos servidores da guarda municipal de patrulhamento preventivo exige do agente em diversos momentos uma pronta resposta, tanto por necessidade da população, quanto em seu dever legal, pois a Lei Federal no 13.022 (BRASIL, 2014) em seu artigo terceiro, determina como princípio mínimo de atuação dos guardas municipais a proteção dos direitos humanos fundamentais, a preservação da vida, redução do sofrimento, diminuição de perdas, patrulhamento preventivo, compromisso com a evolução social da comunidade e uso progressivo da força, e as ocorrências podem ter real necessidade de uso de arma de fogo, dependendo do nível da injusta agressão desferida pelo infrator, gerando risco de vida.

O objetivo foi alcançado por meio da análise dos materiais quantitativos e qualitativos coletados. Os dados da violência demonstraram-se elevados e a sua maioria com crescimento, principalmente nos casos de crimes que envolvem possíveis 
participações pelas guardas municipais nas ruas cariocas em seu cotidiano, como de homicídios dolosos, latrocínios, furtos e roubo de veículos, etc.

Através do questionário, apurou-se que os servidores que trabalham diariamente nas ruas, na sua grande maioria, tanto aprovaram o uso quanto mencionaram já ter passado por ocorrências onde a arma de fogo seria necessária para a conclusão com êxito da mesma, e na questão aberta trouxeram detalhes do perigo que correram sem ter mecanismos para defender a si e a população de ações criminosas que seriam, por lei, sua obrigação. Em resposta à problemática central do artigo: foi descartada a hipótese de exagero no emprego de arma de fogo, e uma real necessidade para desempenho de suas atribuições cotidianas se apresentou. A pesquisa contribuiu para o entendimento da sociedade frente a tal complexidade.

A conclusão do presente trabalho foi de encontro ao que Santos (2018) enfatizou quando citou a essencialidade de armar os guardas municipais para seu funcionamento apropriado, e se mostrou oposta à citação de Baierle e Merlo (2008) onde mencionaram que os guardas municipais de Porto Alegre que trabalham na área operacional são contra a utilização de arma de fogo, diferenciação com a capital carioca pode ter se dado devido a realidade de violência urbana de ambas as capitais.

Como limitação da pesquisa, tem-se a dificuldade de acessibilidade a documentos da instituição, que mesmo não sendo militar, possui regimento e processos hierárquicos rígidos, onde a tramitação de solicitações é morosa, gerando entraves logísticos e temporais.

Recomenda-se a pesquisadores, acadêmicos ou pela sociedade em geral outros tipos de análises, como das questões físicas e psicossociais dos agentes da capital do Rio de Janeiro para o manuseio de armas de fogo através de pesquisas focais, assim como a estrutura logística e de acautelamento de material bélico pela instituição, buscando minimizar a possibilidade de extravio de armas e munições em caso de implementação, como também levantar junto à população da capital carioca sua opinião sobre a temática. 


\section{REFERÊNCIAS}

ANUÁRIO BRASILEIRO DE SEGURANÇA PÚBLICA - 12ª ed. 2018. Disponível em: <http://www.forumseguranca.org.br/wp-content/uploads/2019/02/Anuario-2019-v6infogr\%C3\%A1fico-atualizado.pdf>. Acesso em: 21 de mar. 2019.

BARBOSA, Sérgio Antunes. ANGELO, Ubiratan de Oliveira. Distúrbios Civis: controle e uso da força pela polícia. Rio de Janeiro: Freitas Bastos, 2001.

BAIERLE, Tatiana Cardoso, MERLO, Álvaro Roberto Crespo. Saúde mental e subjetividade no trabalho de uma guarda municipal: estudo em psicodinâmica do trabalho. Cadernos De Psicologia Social Do Trabalho, 11(1), 69-81, 2008.

BRASIL. Lei Federal no 13.022 de 08 de agosto de 2014. Estatuto Geral das Guardas Municipais. Brasília, DF.

BRASÍLIA. SUPREMO TRIBUNAL FEDERAL. Medida Cautelar na Ação Direta de Inconstitucionalidade 5.948. Relator Min. Alexandre de Moraes. BRASíLIA, 2018. Disponível em: <http://www.stf.jus.br/arquivo/cms/noticiaNoticiaStf/anexo/ADI5948MCGuardasmunic ipais.pdf>. Acesso em: 14 de dez. 2018.

CARDEAL, Camila. Arma de fogo para quê? Uma análise da percepção dos Guardas Municipais de Betim. Revista Três Pontos, v. 12, n. 2, 2015.

COSTA, Barbara Regina Lopes. Bola de Neve Virtual: O Uso das Redes Sociais Virtuais no Processo de Coleta de Dados de uma Pesquisa Científica. Revista Interdisciplinar de Gestão Social, v. 7, n. 1, 2018.

DA SILVA, Luciana Alves; CASAGRANDE, Elaine Glaci Fumagalli Errador. Porte de Arma para Guardas Municipais de Municípios com Menos de 500 mil Habitantes. Revista Eletrônica Direito, Justiça e Cidadania - Volume 1 - no 1 - 2010 
DIAS, Walquenis de Oliveira; MADDARENA, Guilherme Lopes; ROCHA, Mainar Feitosa da Silva; SANTOS, Cláudio Pereira. CURSO DE EXTENSÃO EM EQUIPAMENTOS NÃO LETAIS I (CENL-1). UPF-I/ENL-I, 2009. Disponível em: $<$ http://www.pf.gov.br/servicos-pf/seguranca-privada/legislacao-normas-eorientacoes/manual-do-vigilante/manual-dovigilante/Caderno\%20Didatico\%20CENL\%20I.pdf>. Acesso em: 15 de dez. 2018.

DINIZ, Eugênio; JÚNIOR, Domício Proença; MUNIZ, Jaqueline. USO DE FORÇA E OSTENSIVIDADE NA AÇÃO POLICIAL. Universidade Cândido Mendes, 2011. Disponível em: <https://www.ucamcesec.com.br/wp-content/uploads/2011/06/Usode-força-e-ostensividade.pdf>. Acesso em: 12 de dez. 2018.

GIL, Antonio Carlos. Métodos e técnicas de pesquisa social - 6. ed. - São Paulo: Atlas, 2008.

IBGE. Perfil dos Municípios. Brasília, 2012a. Disponível em: $<\mathrm{ftp}: / /$ ftp.ibge.gov.br/Perfil_Municipios/2012/pdf/tab037.pdf>. Acesso em 15 de dez.2018.

IBGE. Perfil dos Municípios. Brasília, 2012b. Disponível em: <ttp://ftp.ibge.gov.br/Perfil_Municipios/2012/pdf/tab038.pdf>. Acesso em: 15 de dez.2018.

METELO, Everson Cézar Gomes. Uso da força nas ações policiais: uma realidade de Mato Grosso. RHM - Vol 10 - Jan/Jun 2013, p. 68-81.

MIRANDA, Ana Paula Mendes de; FREIRE, Letícia de Luna; PAES, Vivian Ferreira. A gestão de segurança pública municipal no Estado do Rio de Janeiro. Rev. Brasileira de Segurança Pública, ano 2 ed. 3 jul/ago 2008.

MOREIRA, Cícero Nunes; CORRÊA, Marcelo Vladimir. Manual de Pratica Policial. Belo Horizonte, 2001. 
RIO DE JANEIRO. Lei Orgânica Municipal (1990). Câmara Municipal do Rio de Janeiro, RJ.

Disponível em:

http://www.rio.rj.gov.br/dlstatic/10112/4946719/4126916/Lei_Organica_MRJ_comaltd 0205.pdf>. Acesso em: 21 de mar. 2019.

RAUPP, Fabiano Maury; BEUREN, Ilse Maria. Metodologia da Pesquisa Aplicável às Ciências. Como elaborar trabalhos monográficos em contabilidade: teoria e prática. São Paulo: Atlas, 2006.

SANTOS, Igor Vieira dos. Guarda Municipal: a possibilidade do porte de armas de fogo e seu impacto na segurança pública. Direito-Tubarão, 2018.

SERRES, Michel. Polegarzinha. Rio de Janeiro: Bertrand Brasil, 2013.

SILVA JUNIOR, Adilson Moreira da; SILVA, Angélica Maria da; COSTA, José Américo Cabral. As atividades da guarda municipal de Volta Redonda e a relevância do porte de armas no exercício da função. Disponível em: < https://app.uff.br/riuff/bitstream/1/6277/1/Adilson\%20Moreira\%20\%20Ang\%C3\%A9lica\%20Maria\%20-\%20Jos\%C3\%A9\%20Am\%C3\%A9rico.pdf>. Acesso em: 26 de fev. 2019.

2.

<http://mail.camara.rj.gov.br/Apl/Legislativos/scpro1720.nsf/f6d54a9bf09ac23303257 9de006bfef6/08de27b4a63d0978832583360069533c?OpenDocument>. Acesso em: 21 de mar. 2019.

3. Disponível em: <https://brasil.estadao.com.br/noticias/rio-de-janeiro,em-plebiscitoniteroi-decide-nao-armar-sua-guarda-municipal,70002065762>. Acesso em: 17 de abr. 2019.

4. Disponível em: <https://extra.globo.com/emprego/servidor-publico/mais-de-80-dosguardas-municipais-sao-favor-do-uso-de-arma-de-fogo-em-servico-23514541.html>. Acesso em: 17 de abr. 2019. 
5. Disponível em: <https://pt.surveymonkey.com/>.

6. Disponível em: <https://g1.globo.com/rj/rio-de-janeiro/noticia/2018/08/10/cresce72-numero-de-mortes-violentas-no-rj-diz-forum-brasileiro-de-segurancapublica.ghtml>. Acesso em 17.04.2019.

7. Informações disponíveis em: <http://maisseguro.rio/>. Acesso em 16 de abr. 2019. Enviado: Julho, 2019.

Aprovado: Agosto, 2019. 